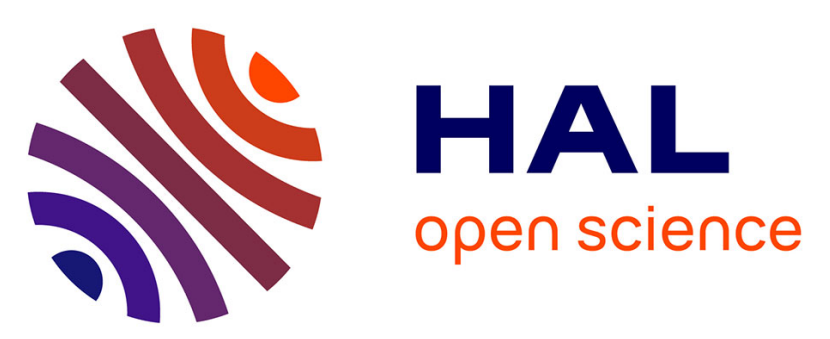

\title{
ATTITUDES TOWARDS THE EXTENSION OF SMOKING RESTRICTIONS TO SELECTED OUTDOOR AREAS IN ITALY
}

Silvano Gallus, Valentina Rosato, Piergiorgio Zuccaro, Paolo Colombo, Marco Manzari, Carlo La Vecchia

\section{To cite this version:}

Silvano Gallus, Valentina Rosato, Piergiorgio Zuccaro, Paolo Colombo, Marco Manzari, et al.. ATTITUDES TOWARDS THE EXTENSION OF SMOKING RESTRICTIONS TO SELECTED OUTDOOR AREAS IN ITALY. Tobacco Control, 2011, 21 (1), pp.59. 10.1136/tc.2010.040774 . hal00677618

\section{HAL Id: hal-00677618 \\ https://hal.science/hal-00677618}

Submitted on 9 Mar 2012

HAL is a multi-disciplinary open access archive for the deposit and dissemination of scientific research documents, whether they are published or not. The documents may come from teaching and research institutions in France or abroad, or from public or private research centers.
L'archive ouverte pluridisciplinaire HAL, est destinée au dépôt et à la diffusion de documents scientifiques de niveau recherche, publiés ou non, émanant des établissements d'enseignement et de recherche français ou étrangers, des laboratoires publics ou privés. 
ATTITUDES TOWARDS THE EXTENSION OF SMOKING RESTRICTIONS TO SELECTED OUTDOOR AREAS IN ITALY

Silvano Gallus ${ }^{1}$, Valentina Rosato ${ }^{1}$, Piergiorgio Zuccaro ${ }^{2}$, Roberta Pacifici ${ }^{2}$, Paolo Colombo ${ }^{3}$, Marco Manzari ${ }^{4}$, Carlo La Vecchia ${ }^{1,5}$

${ }^{1}$ Istituto di Ricerche Farmacologiche "Mario Negri”, 20156 Milan, Italy

${ }^{2}$ Dipartimento del Farmaco, Istituto Superiore di Sanità, 00161 Rome, Italy

${ }^{3}$ Istituto DOXA, Gallup International Association, 20144 Milan, Italy

${ }^{4}$ Dipartimento di Traumatologia, Ortopedia e Medicina del Lavoro, Università degli Studi di Torino, 10126 Turin, Italy

${ }^{5}$ Dipartimento di Medicina del Lavoro "Clinica del Lavoro Luigi Devoto”, Università degli Studi di Milano, 20133 Milan, Italy

Keywords: Epidemiology; Italy; Population survey; Smoking ban; Tobacco smoking.

\section{Correspondence to:}

Silvano Gallus, ScD

Department of Epidemiology

Istituto di Ricerche Farmacologiche Mario Negri

Via La Masa 19, 10156 Milano

tel: +390239014657 - fax: +390233200231 -

e-mail: silvano.gallus@marionegri.it

Word count: 1530 


\section{ABSTRACT}

Objectives: To estimate the attitudes of Italians over the extension of the smoking ban to selected public outdoor areas, including parks, stadiums, beaches, schools and hospitals.

Methods: We considered data from 2 Italian surveys on smoking conducted in 2009 and 2010 on a total sample of 6233 individuals, representative of the Italian population aged 15 years or over.

Results: The majority of the Italian population was in favour of the extension of smoking bans to selected outdoor areas: $64.6 \%$ of Italians supported smoke-free policies in public parks, $68.5 \%$ in sports stadiums, $62.1 \%$ in beaches, $85.9 \%$ in school courtyards and $79.9 \%$ in outdoor areas surrounding hospitals. Among current smokers, the corresponding estimates were $32.9 \%$ for parks, $38.2 \%$ for stadiums, $31.2 \%$ for beaches, $67.6 \%$ for schools and $55.3 \%$ for hospitals. Women, middle-age population and the elderly, subjects from central and southern Italy, and never smokers were more frequently in favour of the extension of the smoking ban to outdoor areas. Support for smoke-free parks and stadiums significantly increased between 2009 and 2010.

Conclusions: Extension of smoking ban to selected outdoor areas is supported by the large majority of the Italian population. The overwhelming majority of support for smoke-free school grounds and outdoor areas surrounding hospitals indicates that legislative action is required. 


\section{INTRODUCTION}

In order to reduce the harms of second-hand smoke (SHS) [1], comprehensive smoke-free legislation banning smoking in all indoor public places came into force in January 2005 in Italy [24]. This law was effective in removing SHS exposure from indoor workplaces [5-7] and reduced cardiovascular and respiratory events, particularly in non smokers [8-10]. Moreover, this highly supported and almost universally observed legislation decreased smoking prevalence and consumption in Italy [2-4]..

An extension of these restrictions to outdoor areas surrounding schools, universities, hospitals, public parks, recreational areas and beaches has been recently suggested. Accordingly, the International Olympic Committee and the Fédération Internationale de Football Association (FIFA) have promoted smoke-free open-air stadiums in the latest editions of the Olympic Games and Football World Cup.

To date, however, outdoor smoking bans remain uncommon $[7,11,12]$. Consequently, scanty data are available on the impact of outdoor smoking bans on SHS exposure and smoking prevalence. However, a recent US survey based on 1910 counselors and 417 administrators of substance abuse treatment organizations showed that current tobacco users were less frequent in organizations with comprehensive bans regulating also outdoor areas, compared to organizations with indoor-only smoking bans [13]. Moreover, non-smokers are exposed to SHS including in outdoor places [1416], and any exposure to SHS is harmful, also in outdoor areas with small buffer zone distances (e.g., bus stops, sport stadiums, hospital grounds, areas surrounding schools, universities, outdoor bars and restaurants) $[17,18]$. Furthermore, outdoor restrictions on smoking may help make tobacco use less socially acceptable, establishing positive smoke-free role models for youth $[7,11,17,19$, 20], reducing (youth) opportunities to smoke, fire hazards, and the pollution generated by cigarette butts (non-biodegradable litter) in public parks and beaches [7, 11, 19-21]. Thus, extensions of smoking regulations to outdoor areas are a promising tool for tobacco control [22-24]. 
The process of adoption of smoke-free legislation in any jurisdiction occurs within both a social and political context [7]. One of its main determinants is the support for restrictions in the community [7]. Given the limited information available on the issue, particularly in Europe [7, 11], we investigated attitudes over the extension of the smoking ban to selected outdoor areas in Italy, a country where the smoke-free legislation did not regulate outdoor areas, and voluntary outdoor bans are only rarely adopted in the hospitality as well as in other settings, including schools and hospitals.

\section{MATERIALS AND METHODS}

We analyzed data from 2 Italian face-to-face, computer-assisted personal in-house interview (CAPI) surveys on smoking [25, 26]. The first survey was conducted in March-April 2009 on a sample of 3213 individuals (1546 males and 1667 females) [26] and the second one in March-April 2010 on a sample of 3020 individuals (1453 males and 1567 females) [25]. The individuals were representative of the Italian population aged 15 years or over in terms of age, sex, geographic area, and socioeconomic characteristics.

The questionnaires included general information on socio-demographic characteristics and on smoking habits, including smoking status (never/ex-/current smoker) and number of cigarettes smoked per day. Current smokers were participants who smoked 100 or more cigarettes in their lifetimes; never smokers were participants who did not smoke in their lifetimes more than 100 cigarettes; ex-smokers were participants who had quit smoking more than 1 year before. The 2009 questionnaire included two questions referring to the degree of support of the smoking ban implemented in 2005. Both surveys included questions on the attitudes towards extension of smokefree regulation to selected outdoor areas, including public parks and gardens, and stadiums. Furthermore, the 2009 survey included a question on the attitudes towards extension of smoke-free regulation to beaches, and the 2010 survey to school courtyards and gardens, courtyards or outdoor 
areas of hospitals. Each question had a structured four-item score (strongly in favour, moderately in favour, moderately against and strongly against).

The odds ratios (OR) and the corresponding 95\% confidence intervals (CI) for being moderately to strongly in favour vs moderately to strongly against various smoking bans, according to selected characteristics, were derived using unconditional multiple logistic regression models after adjustment for sex, age, geographic area, level of education, smoking habit and year of interview.

\section{RESULTS}

Overall, jointly considering the surveys conducted in 2009 and 2010, 23.6\% of Italians aged 15 or over described themselves as current cigarette smokers (26.4\% of males, $21.0 \%$ of females).

Figure 1 shows the attitudes of the Italian population towards the (extension of the) smoke-free legislation that came into force in 2005 . Four years after the implementation of the indoor smoking ban, $95.8 \%$ (89.0\% of current smokers) were moderately to strongly in favour of smoke-free policies in public areas and 93.9\% (85.4\% of current smokers) in indoor workplaces. Overall, $64.6 \%$ of Italians supported smoke-free public parks, $68.5 \%$ sports stadiums, $62.1 \%$ beaches, $85.9 \%$ school courtyards and $79.9 \%$ in outdoor areas surrounding hospitals. Among current smokers, the corresponding estimates were $32.9 \%$ for parks, $38.2 \%$ for stadiums, $31.2 \%$ for beaches, $67.6 \%$ for schools and $55.3 \%$ for outdoor areas surrounding hospitals.

After adjustment for several covariates including tobacco smoking, women were systematically more frequently in favour both of the 2005 smoking ban and of the extension of the smoking ban to outdoor areas (Table 1). A direct relation with age was evident, the young being less favourable to the extension of the smoking ban. Subjects from central and southern Italy were systematically more frequently in favour of the extension of the smoking ban to outdoor areas. No specific pattern was evident according to level of education. Compared with never smokers, current smokers were less in favour of various smoking restrictions, the multivariate ORs ranging between 0.1 and 0.2. 
Also former smokers were systematically less favourable than never smokers to an extension of the smoking bans, the ORs ranging between 0.5 and 0.7 for various outdoor areas considered. Italians supporting an extension of the legislation significantly increased between 2009 and 2010 for gardens and parks and sports stadiums.

\section{DISCUSSION}

This is among the first studies - and to our knowledge the first European study - providing national data on the attitudes towards smoke-free outdoor areas. In our study, approximately two thirds of the Italian population support an extension of the smoking ban to outdoor public places, including public parks, stadiums and beaches, and more than four out of five Italian adults are favourable to smoke-free policies in school courtyards and in outdoor areas surrounding hospitals, with an appreciable support also among current smokers. Support for smoke-free parks and stadiums significantly increased between 2009 and 2010.

Our findings are in agreement with a few recent US studies [7]. A survey of 1501 adults from Minnesota in 2004 showed that $70 \%$ of the general public supported smoke-free parks (77\% of nonsmokers, but only $33 \%$ of smokers) [20]. In 2006, a population survey showed that $59 \%$ of Californians preferred smoke-free public beaches; in 2007 this prevalence increased to $67 \%$ [27]. In the 2002 California Tobacco Survey, 43\% supported smoke-free regulations in outdoor workplaces, $52 \%$ in outdoor public places, $63 \%$ outside building entrance, $79 \%$ in campus student housing and 91\% in kids' playing yards/fields [28]. These estimates increased in the 2005 California Tobacco Survey [29]. Moreover, in four California Tobacco Surveys conducted between 1993 and 2002 on approximately 24,000 adolescents aged 12 to 17 , students strongly supported smoke-free school grounds (more than 85\% each survey year for non-smokers, and from 56\% in 1996 to $69 \%$ in 2002 among current smokers) [30]. 
Thus, support for extension of outdoor smoking bans is increasing worldwide [11], mirroring the experience with indoor restrictions [3, 7]. In Italy, for example, in $200183 \%$ of the population was in favour of banning smoking in all indoor public areas, including restaurants and bars [31]. This increased to $90 \%$ in 2005 , immediately after the implementation of the Italian legislation [2], to $94 \%$ in 2006 [3] and to $96 \%$ in 2009. Similar patterns were observed also with reference to indoor workplaces. These findings suggest that support for smoking bans increases after the adoption of the legislation $[2,11,32,33]$.

Obtaining a broad consensus in the community about smoke-free policies facilitates the adoption of the regulation and its compliance [7]. Once smoking ban policies are adopted, compliance can be improved: for example, a study conducted in a US college campus showed that the use of a multiple component package, including moving receptacles, marking the ground, improving signage, and distributing reinforcements and reminder cards, substantially increases the proportion of smokers complying with the smoking ban policy [34].

Potential limitations of the study include those inherent to the sampling design, such as selection bias and information bias due to self-reporting. Moreover, in our surveys we asked about support for smoke-free bans, but not priorities. Strengths of our surveys include the relatively large sample size and its representativeness of the Italian adult population.

In conclusion, the large majority of the Italian population supports the extension of smoking ban to selected outdoor areas, including parks, sports stadiums and beaches. The high levels of support, particularly for smoke-free school grounds and areas surrounding hospitals, indicate that further legislative action is required in Italy. Our findings confirm the feasibility of extending smoke-free legislation to outdoor places and provide priority indicators of where to enact these policies. 


\section{"What this paper adds" box}

\section{What is already known on this subject?}

Extensions of smoking regulations to outdoor areas are a promising tool for tobacco control, but outdoor smoking bans remain uncommon.

The successful adoption of smoke-free legislation is influenced by public support for restrictions. Scanty information is available on the issue, particularly in Europe.

\section{What does this study add?}

Using data from 2 representative surveys conducted in Italy, we found that extension of smoking restrictions to selected outdoor areas is supported by the large majority of the Italian population.

Our findings confirm therefore the feasibility of extending smoke-free legislation to outdoor places and provide priority indicators of where to enact these policies.

\section{Competing interests: None.}

Funding: This work was conducted with contributions from the Italian Ministry of Health, the Italian League Against Cancer and the Italian Association for Cancer Research.

Contributors: SG had the original idea for the study; SG, CLV and MM gave substantial contributions to conception, design and interpretation of data; PC, RP and PZ gave contributions to conception and design of the study and provided data from the surveys; VR conducted the data analysis; SG drafted the manuscript, all the other authors critically contributed to the revision of the article for important intellectual content; all the authors approved the final version of the manuscript.

Copyright licence statement: The Corresponding Author has the right to grant on behalf of all authors and does grant on behalf of all authors, an exclusive licence on a worldwide basis to the 
BMJ Group and co-owners or contracting owning societies (where published by the BMJ Group on their behalf), and its Licensees to permit this article (if accepted) to be published in Tobacco Control and any other BMJ Group products and to exploit all subsidiary rights, as set out in our licence. 


\section{References}

[1] IARC. IARC Monographs on the Evaluation of the Carcinogenic Risks to Humans. Vol. 83. Tobacco smoke and involunary smoking: IARC, Lyon 2004.

[2] Gallus S, Zuccaro P, Colombo P, et al. Effects of new smoking regulations in Italy. Ann Oncol 2006;17:346-7.

[3] Gallus S, Zuccaro P, Colombo P, et al. Smoking in Italy 2005-2006: effects of a comprehensive National Tobacco Regulation. Prev Med 2007;45:198-201.

[4] Tramacere I, Gallus S, Fernandez E, et al. Medium-term effects of Italian smoke-free legislation: findings from four annual population-based surveys. J Epidemiol Community Health 2009;63:559-62.

[5] Gorini G, Costantini AS, Paci E. Smoking prevalence in Italy after the smoking ban: towards a comprehensive evaluation of tobacco control programs in Europe. Prev Med 2007;45:123-4.

[6] Gorini G, Gasparrini A, Tamang E, et al. Prevalence of second-hand smoke exposure after introduction of the Italian smoking ban: the Florence and Belluno survey. Tumori 2008;94:798-802.

[7] IARC. IARC Handbooks of Cancer Prevention. Volume 13. Evaluating the effectiveness of smoke-free policies. Lyon, France. International Agency for Research on Cancer. 2009.

[8] Barone-Adesi F, Vizzini L, Merletti F, et al. Short-term effects of Italian smoking regulation on rates of hospital admission for acute myocardial infarction. Eur Heart J 2006;27:2468-72.

[9] Cesaroni G, Forastiere F, Agabiti N, et al. Effect of the Italian smoking ban on population rates of acute coronary events. Circulation 2008;117:1183-8.

[10] Bianchi M, Campi R, Bonati M. Smoke-free legislation and asthma. N Engl J Med $2011 ; 364: 87-8$.

[11] Thomson G, Wilson N, Edwards R. At the frontier of tobacco control: a brief review of public attitudes toward smoke-free outdoor places. Nicotine Tob Res 2009;11:584-90. 
[12] Kennedy RD, Elton-Marshall T, Mutti S, et al. Understanding the impact of the Smoke-Free Ontario Act on hospitality establishments' outdoor environments: a survey of restaurants and bars. Tob Control 2010;19:165-7.

[13] Knudsen HK, Boyd SE, Studts JL. Substance abuse treatment counselors and tobacco use: a comparison of comprehensive and indoor-only workplace smoking bans. Nicotine Tob Res 2010;12:1151-5.

[14] Sureda X, Fu M, Lopez MJ, et al. Second-hand smoke in hospitals in Catalonia (2009): a cross-sectional study measuring PM2.5 and vapor-phase nicotine. Environ Res 2010;110:750-

5.

[15] Brennan E, Cameron M, Warne C, et al. Secondhand smoke drift: examining the influence of indoor smoking bans on indoor and outdoor air quality at pubs and bars. Nicotine Tob Res 2010;12:271-7.

[16] Cameron M, Brennan E, Durkin S, et al. Secondhand smoke exposure (PM2.5) in outdoor dining areas and its correlates. Tob Control 2010;19:19-23.

[17] Chapman S. Banning smoking outdoors is seldom ethically justifiable. Tob Control 2000;9:95-7.

[18] Klepeis NE, Ott WR, Switzer P. Real-time measurement of outdoor tobacco smoke particles. J Air Waste Manag Assoc 2007;57:522-34.

[19] Arcus J, Boey S, Bradshaw R, et al. SMOKES 2007 - Smoking outdoors in a kids environment: a pilot study: evaluating the Upper Hutt City Council smokefree parks policy. Wellington, New Zealand, University of Otago. Available online at: http://www.smokefreecouncils.org.nz/fileadmin/clients/cancer_society/pdf/The_SMOKE_stu dy_2007_report_FINAL.pdf. 2007.

[20] Klein EG, Forster JL, McFadden B, et al. Minnesota tobacco-free park policies: attitudes of the general public and park officials. Nicotine Tob Res 2007;9 Suppl 1:S49-55. 
[21] Bloch M, Shopland DR. Outdoor smoking bans: more than meets the eye. Tob Control 2000;9:99.

[22] Knudsen HK, Boyd SE, Studts JL. Substance Abuse Treatment Counselors and Tobacco Use: A Comparison of Comprehensive and Indoor-Only Workplace Smoking Bans. Nicotine Tob Res 2010 .

[23] Warner KE, Mendez D. Tobacco control policy in developed countries: Yesterday, today, and tomorrow. Nicotine Tob Res 2010;12:876-87.

[24] Francis JA, Abramsohn EM, Park HY. Policy-driven tobacco control. Tob Control 2010;19 Suppl 1:i16-20.

[25] Gallus S, Muttarak R, Martinez Sanchez JM, et al. Smoking prevalence and smoking attributable mortality in Italy, 2010. Prev Med 2011; In press.

[26] Tramacere I, Gallus S, Pacifici R, et al. Smoking in young and adult population, Italy 2009. Tumori 2011; In press.

[27] California Department of Health Services. California tobacco control program. Califorina tobacco control update 2009: 20 years of tobacco control in California. Sacramento, CA. Available online at: http://www.cdph.ca.gov/programs/tobacco/Documents/CTCPUpdate2009.pdf. 2009.

[28] Gilpin EA, Lee L, Pierce JP, et al. Support for protection from secondhand smoke: California 2002. Tob Control 2004;13:96.

[29] Al-Delaimy WK, White MM, Trinidad DR, et al. The California Tobacco Control Program: Can we Maintain the Progress? Results from the California Tobacco Survey, 1990-2005. Volume 2. La Jolla, CA, University of California, San Diego. Available online at: http://libraries.ucsd.edu/ssds/tobacco.htm\#2005. 2008.

[30] Trinidad DR, Gilpin EA, Pierce JP. Compliance and support for smoke-free school policies. Health Educ Res 2005;20:466-75. 
[31] La Vecchia C, Garattini S, Colombo P, et al. Attitudes towards smoking regulation in Italy. Lancet 2001;358:245.

[32] Gilpin EA, Lee L, Pierce JP. Changes in population attitudes about where smoking should not be allowed: California versus the rest of the USA. Tob Control 2004;13:38-44.

[33] Jamrozik K. Population strategies to prevent smoking. BMJ 2004;328:759-62.

[34] Harris KJ, Stearns JN, Kovach RG, et al. Enforcing an outdoor smoking ban on a college campus: effects of a multicomponent approach. J Am Coll Health 2009;58:121-6. 
Figure 1: Percent prevalence (\%) of the Italian population, separately among non-smokers (never and former) and current smokers, supporting the indoor smoking ban and its extension to selected outdoor areas*, assessed through the question: "Would you be in favour or against (the extension of) the smoking ban in..."

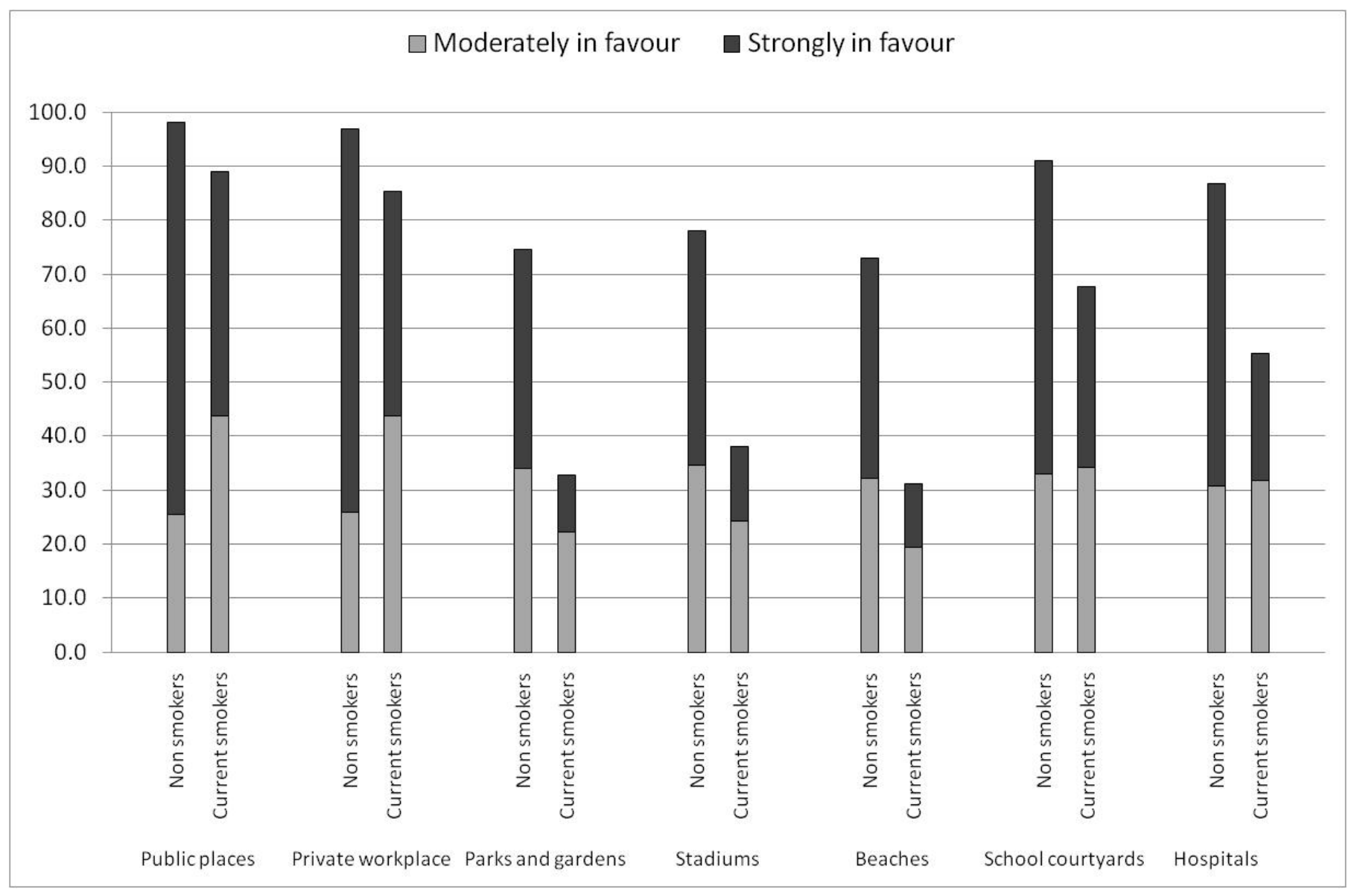

* Attitudes on public places and workplaces and beaches were based on the 2009 survey (3213 participants), those on school courtyards and outdoor areas surrounding hospitals on the 2010 survey (3020 participants) and those on parks and gardens, and stadiums on both the surveys (6233 participants) 
Table 1: Attitudes of the Italian population, overall and in strata of selected characteristics, over the indoor smoking ban and its extension to selected outdoor areas, assessed through the question: "Would you be in favour or against (the extension of) the smoking ban in..."

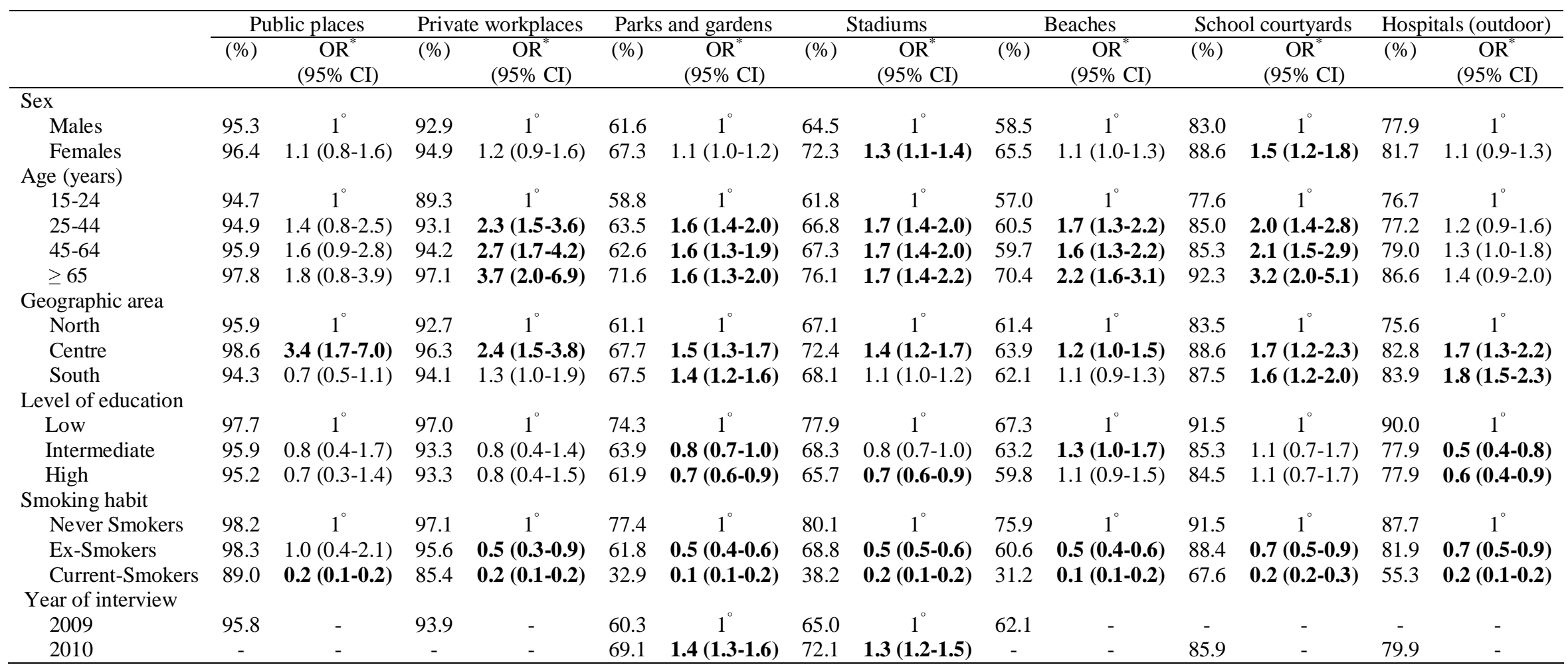

* Estimated using unconditional multiple logistic regression models after adjustment for sex, age, geographic area, level of education, smoking habit and year of interview. Estimates in bold are statistically significant $(\mathrm{p}<0.05)$.

${ }^{\circ}$ Reference category 